2007-01-01

\title{
Analysis of supercritical stratified tidal flow in a Scottish Fjord
}

Stashchuk, Nataliya

http://hdl.handle.net/10026.1/3853

10.1175/jpo3087.1

Journal of Physical Oceanography

American Meteorological Society

All content in PEARL is protected by copyright law. Author manuscripts are made available in accordance with publisher policies. Please cite only the published version using the details provided on the item record or document. In the absence of an open licence (e.g. Creative Commons), permissions for further reuse of content should be sought from the publisher or author. 


\title{
Analysis of Supercritical Stratified Tidal Flow in a Scottish Fjord
}

\author{
NATALiYa Stashchuk \\ School of Earth, Ocean and Environmental Sciences, University of Plymouth, Plymouth, United Kingdom \\ MARK INALL \\ Dunstaffnage Marine Laboratory, Scottish Association for Marine Science, Oban, United Kingdom \\ VASILIY VLASENKO \\ School of Earth, Ocean and Environmental Sciences, University of Plymouth, Plymouth, United Kingdom
}

(Manuscript received 14 December 2005, in final form 28 September 2006)

\begin{abstract}
The baroclinic tidal regime of the fjord Loch Etive (Scotland) is studied. Analysis is performed on the basis of both in situ data and numerical simulations, with the use of a fully nonlinear nonhydrostatic fine-resolution model. It was found that the crest of the sill that separates Loch Etive into inner and outer parts is subjected to a supercritical flow regime with maximum Froude numbers in excess of 5. Strong supercritical conditions lead to the formation of flow separation just above the sill's crest. As is inherent to jet-type fjordic systems, this, in turn, leads to a weak nonlinear baroclinic wave response. On the other hand, observations and numerical results also revealed the presence of propagating internal tidal waves with amplitudes up to $10 \mathrm{~m}$, several kilometers from the constriction. It is shown that these baroclinic tidal waves are excited during the ebb phase over a section of the inner flank of the sill, at a depth below $30 \mathrm{~m}$, where the local Froude number is substantially less than unity. Thus Loch Etive simultaneously exhibits both weak nonlinear response due to strong supercritical conditions with flow separation over the sill and a significant linear baroclinic tidal response due to the deeper flank of the sill. In this respect, exhibiting both jet- and wave-type behavior, Loch Etive can be referred to as a "hybrid type" fjord: the authors suggest that many jet-type fjords will also generate a significant baroclinic response and should correctly fit into this new category.
\end{abstract}

\section{Introduction}

Geological structures developed by glacial erosion and partly filled with the seawater can be found along the coasts of North and South America (poleward to $42^{\circ}$ ), Kerguelen Islands, South Georgia, Russian and Canadian arctic archipelagos, New Zealand, Antarctica, Greenland, Norway, Iceland, and northern United Kingdom. They are called fjords, sounds, inlets, or arms, depending on the country. On the west coast of Scotland they are called "sea lochs." Despite such a large number of names these features are usually narrow and steep sided, extending below sea level, and

Corresponding author address: Dr. Nataliya Stashchuk, School of Earth, Ocean and Environmental Sciences, University of Plymouth, Drake Circus PSQ A504, Plymouth PL4 8AA, United Kingdom.

E-mail: nataliya.stashchuk@plymouth.ac.uk possess one or more submarine sills, which define the deep basin(s), and there is usually a river discharging into the head.

The presence of sills and narrows restricts the exchange of water between the open sea and the semienclosed part of the fjord. Usually the deep water is trapped behind a shallow sill and is able to penetrate through the sill by the action of two processes: (i) inflowing water of higher density that sinks and replaces the existing water mass (renewal) and (ii) vertical mixing due to turbulent and molecular diffusion (e.g., Liungman 2000). Time periods when only the diffusive processes are active are commonly termed stagnant periods, referring to the poor ventilation and the possible development of anoxic conditions. Renewal involves dense bottom currents and is usually a rapid process, such that an entire basin may be renewed within several days. Diffusion, on the other hand, is a slow process, sometimes involving time scales of years. However,

DOI: $10.1175 / \mathrm{JPO} 3087.1$

(C) 2007 American Meteorological Society 


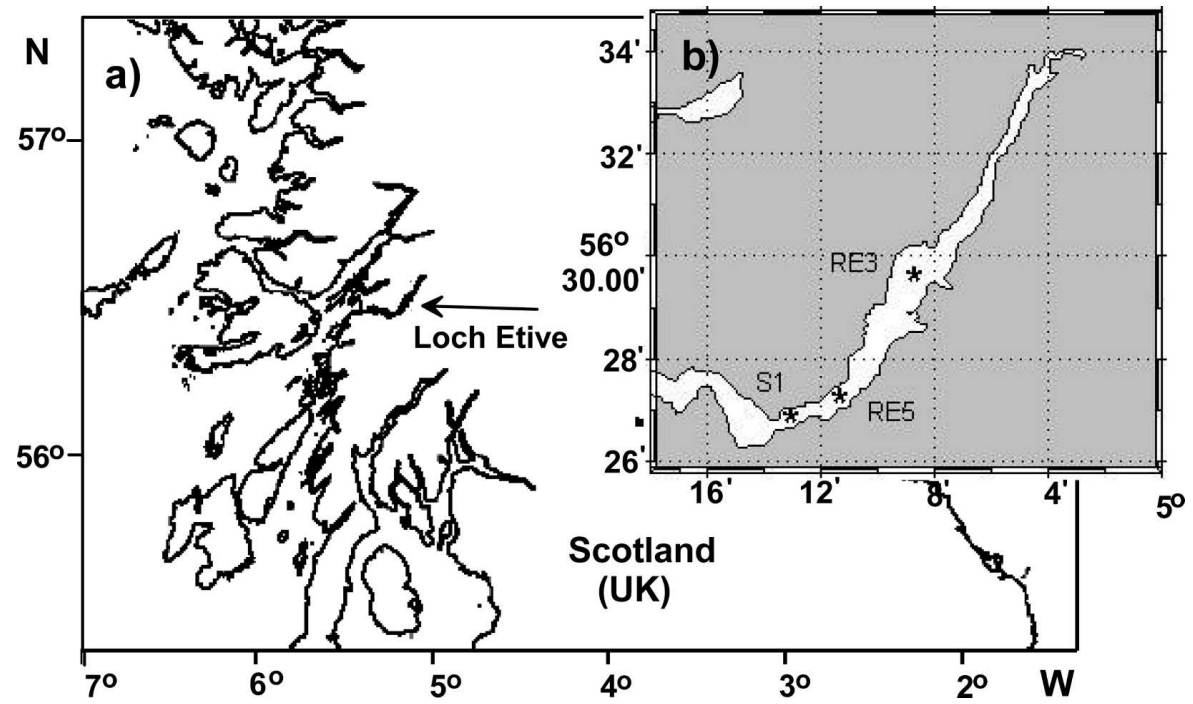

FIG. 1. (a) Location map of Loch Etive and (b) coastal outline of Loch Etive fjord system showing the positions of moored instruments at S1, RE5, and RE3.

through diffusion, slow penetration of freshwater into the deep waters of the sill basin is possible (Farmer and Freeland 1983).

Water renewal is an intermittent phenomenon, which is why it is important to understand the role of tides in mixing around the sill, because the vertical mixing, which essentially preconditions the deep water for its subsequent renewal, is mainly driven by sill-generated internal tides.

Defining $U$ as a maximum value of tidal velocity over the sill and $c$ as the phase speed of an internal wave, then from the hydraulic point of view (Farmer and Freeland 1983; Stigebrandt and Aure 1989) the supercritical conditions, for which $U>c$, imply that the kinetic energy exceeds potential energy of the baroclinic field, thus inhibiting the development of wavelike behavior.

According to the criterion $U>2 c / 3$ or $U<2 c / 3$, all fjords were divided by Stigebrandt and Aure (1989) into jet type and wave type. In the first case the tidal jet is assumed to be too fast for internal wave generation. Later Stigebrandt (1999), investigating the energy transfer from barotropic tides to baroclinic motions, suggested several mechanisms that may cause resistance to barotropic flow in fjords. If $U<c$ we can expect significant baroclinic wave drag ("wave basin"), that is, generation of internal waves by oscillating barotropic flow. The barotropic form drag is expected to dominate when $U>c$ and the flow takes the form of a dissipating jet ("jet basin"). However, the measurements in Loch Etive, which according to this classification can be treated as a typical jet-type fjordic basin, revealed the generation of mode- 1 baroclinic tidal waves (Inall et al. 2004, 2005).
Loch Etive, located on the west coast of Scotland (Fig. 1a), is a 30-km-long sea loch. A basinwide survey in its largest upper basin (Fig. 1b) was undertaken in June 2001 in an attempt to follow the pathways by which the barotropic energy disperses into and dissipates within the loch. Three moorings were deployed along the axis of the basin at stations RE5 (deep, water depth $\sim 145 \mathrm{~m}$ ), RE3 (intermediate, water depth $\sim 60$ $\mathrm{m}$ ), and S1 (on the sill, water depth $\sim 15 \mathrm{~m}$ ): all were instrumented with RDI acoustic Doppler current profilers (ADCPs), Vemco temperature loggers, and Seabird temperature, salinity, pressure sensors (TSP) at levels throughout the water column at stations RE5 and RE3 and a single TSP sensor at S1 on the seabed (Fig. 1b).

At S1 a 1200-kHz ADCP was deployed on the seabed (0.5-m bins, 60-s ensembles, 120 pings per ensemble) with a single TSP sensor (120-s sampling). At RE5 a $300-\mathrm{KHz}$ ADCP was moored in line at $12 \mathrm{~m}$ above the bed ( 8 - $\mathrm{m}$ bins, 120 -s ensembles, 12 pings per ensemble), 10 temperature sensors were deployed with vertical spacing of $10 \mathrm{~m}$ (20-min sampling), and a TSP sensor was at $119 \mathrm{~m}$ above the bed. At RE3 a $600-\mathrm{kHz}$ ADCP was deployed at $5.5 \mathrm{~m}$ above the bed (2-m bins, 60-s ensembles, 40 pings per ensemble), and six temperature sensors were deployed with 8 -m vertical spacing (sample interval $3 \mathrm{~min}$ ). Seabird 911 CTD profiles were taken at all stations at regular intervals throughout the experiment. At station RE5 a salinity-compensated temperature minimum of $9.24^{\circ} \mathrm{C}$ exists at $35 \mathrm{~m}$ (at the surface, the temperature is $12.5^{\circ} \mathrm{C}$, while at the bed it has the value $10.0^{\circ} \mathrm{C}$ ). The temperature inversion reflects the (irregular) timing of the previous deep-water renewal of the basin. 

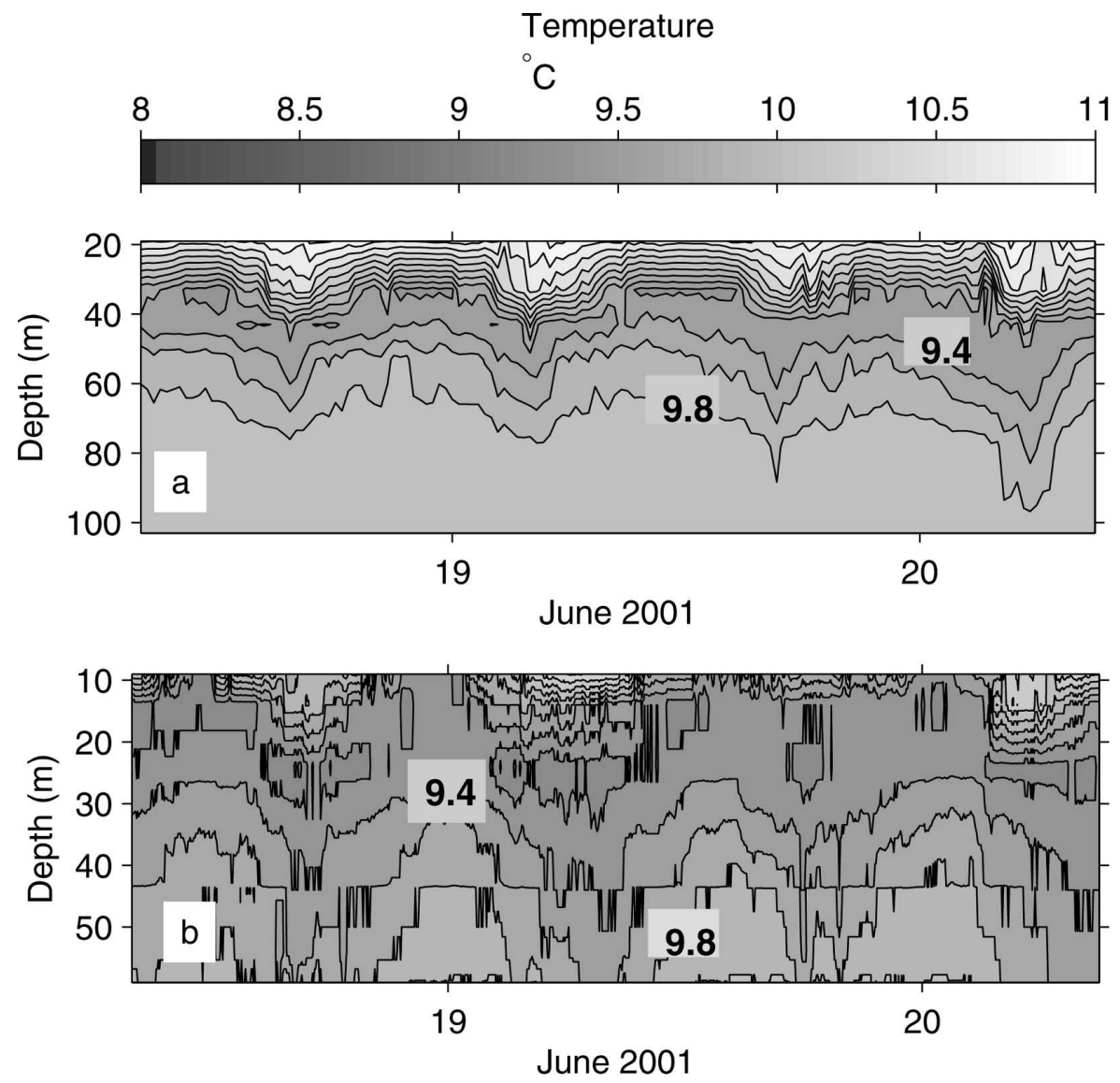

FIG. 2. Vertical temperature structure over four $M_{2}$ tidal cycles at (a) RE5 and (b) RE3. The contour interval equals $0.2^{\circ} \mathrm{C}$.

The moored instruments along the axis of the basin revealed oscillations of the pycnocline below sill depth (up to 10-m amplitude at RE5 and RE3), with characteristics close to a progressive linear harmonic internal wave (Fig. 2). A vessel-mounted $300-\mathrm{kHz}$ ADCP (VMADCP) transect was repeated seven times, running from the deep basin toward the sill. Sailing into the flooding tide on each transect at approximately $1 \mathrm{kt}$, each transect took approximately 35 min to complete. The vertical bin size was set to $2 \mathrm{~m}$; 20 -s ensembles give an effective horizontal resolution of approximately $10 \mathrm{~m}$.

In this paper we describe in detail both the supercritical flow processes at the sill and the simultaneous, linear baroclinic tidal response of the basin. The distinct physical processes at work in these two regimes are explained and an interpretation is offered of the simultaneous wave- and jet-type behavior of this fjord.

The paper proceeds as follows: the mathematical model is described in section 2, section 3 presents the Froude number analysis, and the theoretical and observational investigation of the tidal response of Loch Etive is given in section 4. Section 5 discusses a baro- clinic tidal forcing analysis, a budget of tidal energy is discussed in section 6, and a summary and conclusions are presented in section 7 .

\section{Model description}

Figure 3 shows the studied area of Loch Etive containing a constriction and a sill. It covers the upper basin of Loch Etive, which has a minimum sill depth of $10 \mathrm{~m}$ and a maximum basin depth of $145 \mathrm{~m}$. The bottom topography in the vicinity of the sill is characterized by a U-shaped profile across the channel with steep slopes near the shoreline and a gently sloping bottom far from it. In such a situation a rectangular cross section is a good approximation to the real loch configuration. Far from the sill (in the inner deep basin) the shape of the cross section is more complicated and is best characterized by a V-shaped rather than a U-shaped profile. The use of a rectangular cross section far from the sill is therefore not as accurate as in the sill region. Fortunately, the deep part of the loch is not a place of internal wave generation (as will be shown below), and so 


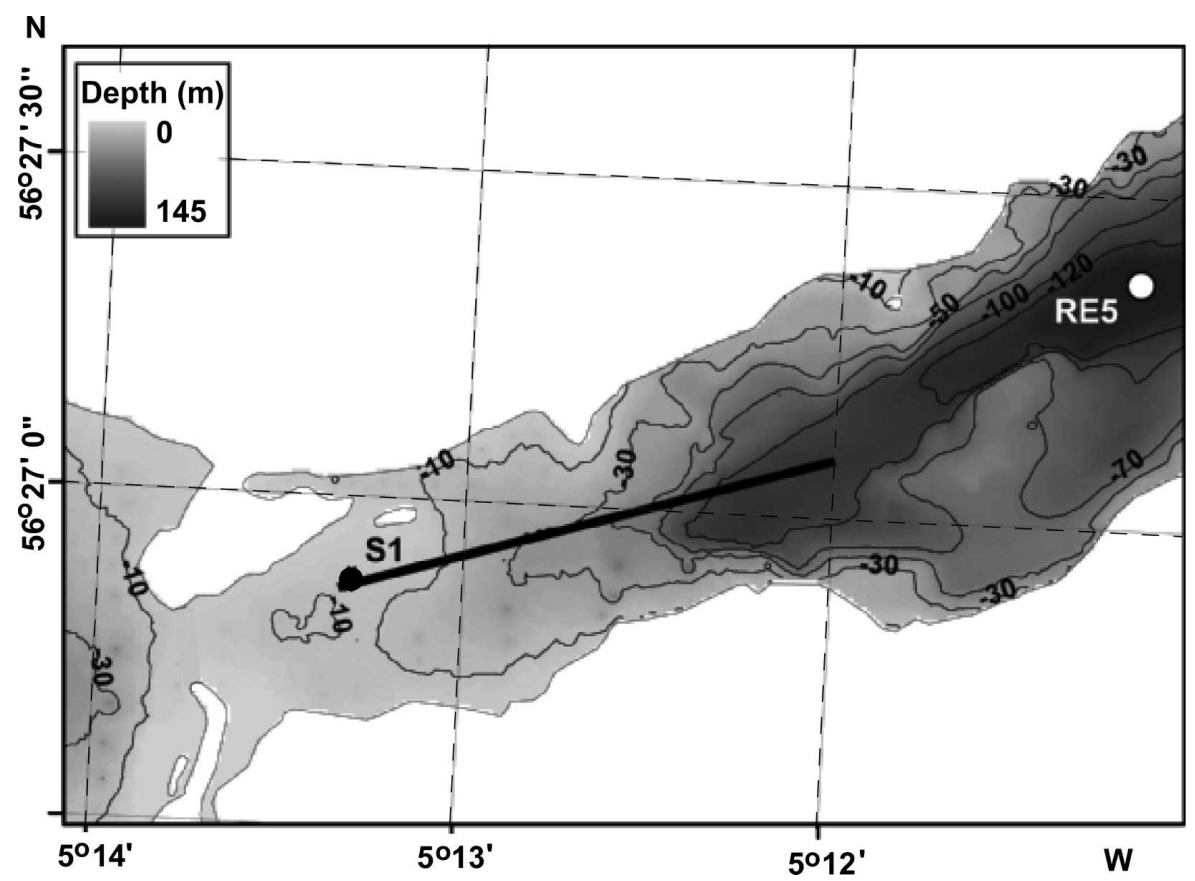

FIG. 3. Detailed bathymetry of the sill area from a side-scan sonar survey. Location of the sill $\mathrm{ADCP}$ (S1), the vessel-mounted ADCP transect (black line), and the mooring at RE5 are shown.

the actual profile of the bottom here is not as important as in the sill region.

In the model the depth beyond the region of the sill is set to be constant $(60 \mathrm{~m}$ seaward and $145 \mathrm{~m}$ landward), and variable cross-channel bottom topography was replaced by a rectangle of the same cross section.

We use the right-handed Cartesian coordinate system, in which the $x$ axis is along the loch with positive $x$ directed landward, the $y$ axis is across the loch bathymetry, and the $z$ axis is directed vertically upward. The bottom topography is assumed to be a function of $x$ only, $H=H(x)$ is a thalweg depth; and the width of the channel is denoted by $2 b(x)$; see Figs. $4 \mathrm{a}$ and $4 \mathrm{~b}$.
The density distribution $\rho_{0}(z)$ for the model calculation was taken from the measurements at station RE5 (Fig. 5a). For the observational buoyancy frequency $N(z)=\left(-g \rho_{0 z} / \rho_{0}\right)^{1 / 2}, g$ is the acceleration due to gravity (dotted line) and its theoretical presentation (solid line) shows that the pycnocline in Loch Etive is very sharp and is located just beneath the free surface (at 4-m depth; see Figs. 5a and 5b).

A nonhydrostatic, fully nonlinear numerical model based on the laterally averaged Reynolds equations in the Boussinesq approximation is applied to the domain (Vlasenko et al. 2002). The system has the form

$$
\begin{gathered}
\Omega_{t}+\frac{J(\Omega, \Psi)}{2 b}-\frac{b_{x} \Omega \Psi_{z}}{2 b^{2}}=g \frac{\rho_{x}}{\bar{\rho}_{0}}+\frac{\left(A_{H} \Psi_{x z}\right)_{x z}+\left(A_{H} \Psi_{x x}\right)_{x x}+\left(A_{V} \Psi_{x z}\right)_{x z}+\left(A_{V} \Psi_{z z}\right)_{z z}}{2 b}-\frac{b_{x}\left[\left(A_{H} \Psi_{x x}\right)_{x}+\left(A_{V} \Psi_{x z}\right)_{z}\right]}{2 b^{2}} \text { and } \\
\rho_{t}+\frac{J(\rho, \Psi)}{2 b}+\frac{\bar{\rho}_{0}}{g} N^{2}(z) \Psi_{x}=\frac{\left(2 b K_{H} \rho_{x}\right)_{x}+\left(2 b K_{V} \rho_{z}\right)_{z}}{2 b}
\end{gathered}
$$

Here $\Psi$ is the streamfunction and $\Omega$ is the vorticity,

$$
\begin{aligned}
u & =\frac{\Psi_{z}}{2 b}, \quad w=-\frac{\Psi_{x}}{2 b}, \quad \text { and } \\
\Omega & =\frac{\Psi_{x x}}{2 b}+\frac{\Psi_{z z}}{2 b}-\frac{b_{x} \Psi_{x}}{2 b^{2}},
\end{aligned}
$$

where $u$ and $w$ are the components of the velocity in the $x$ and $z$ directions, respectively; $\bar{\rho}_{0}$ is a constant average value of density; $\rho=\rho(x, z, t)$ is a wave-induced deviation of the stable undisturbed background density $\rho_{0}(z) ; A_{V}, K_{V}, A_{H}$, and $K_{H}$ are the coefficients of vertical and horizontal eddy viscosity and turbulent diffusion, and $J(A, B)=A_{x} B_{z}-A_{\mathrm{z}} B_{x}$ is the Jacobian operator. 


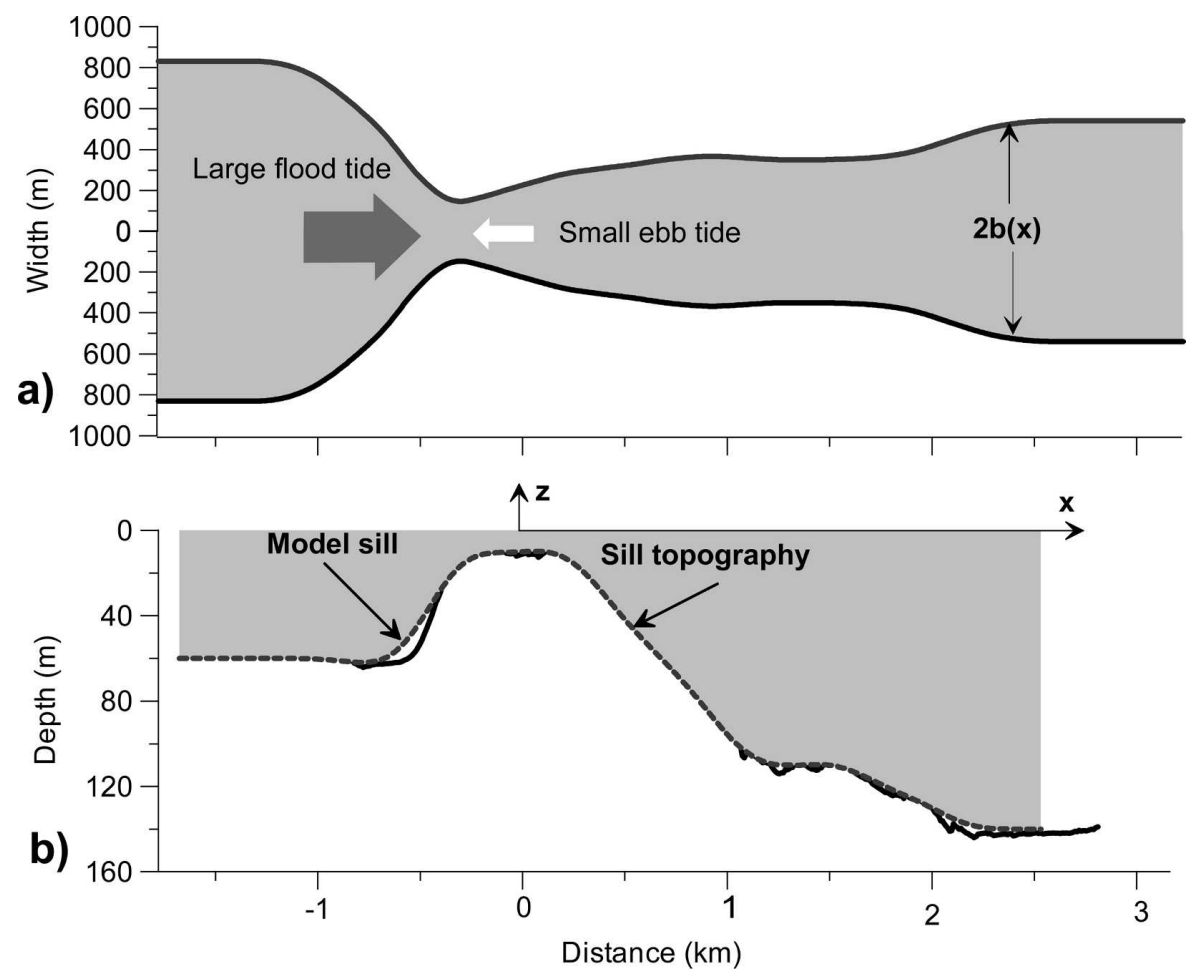

FIG. 4. Schematic diagram of the loch: (a) a plan view of the model channel at the sill; (b) topography of the sill (solid line is real sill; the model sill is shown with a broken line).

The vertical turbulent viscosity $A_{V}$ and diffusivity $K_{V}$ are determined by the Richardson number-dependent parameterization (Pacanowski and Philander 1981), namely,

$$
A_{V}=\frac{A_{0}}{(1+\alpha \mathrm{Ri})^{k}}+A_{b} \quad \text { and } \quad K_{V}=\frac{A_{V}}{1+\alpha \mathrm{Ri}}+K_{b},
$$

where $\mathrm{Ri}$ is the Richardson number

$$
\mathrm{Ri}=\frac{N^{2}(z)}{u_{z}^{2}} .
$$

Here $A_{b}$ and $K_{b}$ are the background dissipation parameters and $A_{0}, \alpha$, and $k$ are the adjustable parameters. Such a parameterization for the vertical turbulent kinematical viscosity $A_{V}$ and diffusivity $K_{V}$ increases their values in the areas where the Richardson number $\mathrm{Ri}$ is small. The application of a Richardson number parameterization gave very robust results for the modeling of supercritical water exchange in the strait of the Dardanelles (Stashchuk and Hutter 2001) and baroclinic tidal dynamics in the Trondheimsfjord (Vlasenko et al. 2002).

The values of horizontal eddy viscosity $A_{H}$ and turbulent diffusion $K_{H}$ were taken as small as possible to allow the effective energy cascading from large to small scales (short internal waves) on the one hand (the large value of the diffusivity suppresses this processes) and to secure the stability of our numerical scheme on the other. The basic series of calculations was performed with the values $A_{H}=K_{H}=0.1 \mathrm{~m}^{2} \mathrm{~s}^{-1}$.

We are only interested here in the baroclinic tidal response of the system, and thus the "rigid lid" approximation for the boundary conditions at the surface $z=0$ is used. Introducing the barotropic tidal forcing as an oscillating tidal flow with the maximum discharge $\Psi_{0}$, the following condition is valid for the streamfunction at the surface:

$$
\Psi(x, 0, t)=\Psi_{0} f(t) \quad \text { and } \quad z=0,
$$

where $f(t)$ is the temporal tidal function, which includes an asymmetry between flood and ebb tide as seen in the observations (Inall et al. 2004). Vanishing mass flux through the water surface and absence of wind forcing at $z=0$ give the following boundary conditions:

$$
\Omega=0 \quad \text { and } \quad \rho_{z}=0 .
$$

The contour $z=-H(x)$ is a streamline through which zero mass flux is required:

$$
\Psi=0, \quad \Omega=\Omega_{0}, \quad \text { and } \quad \rho_{n}=0,
$$



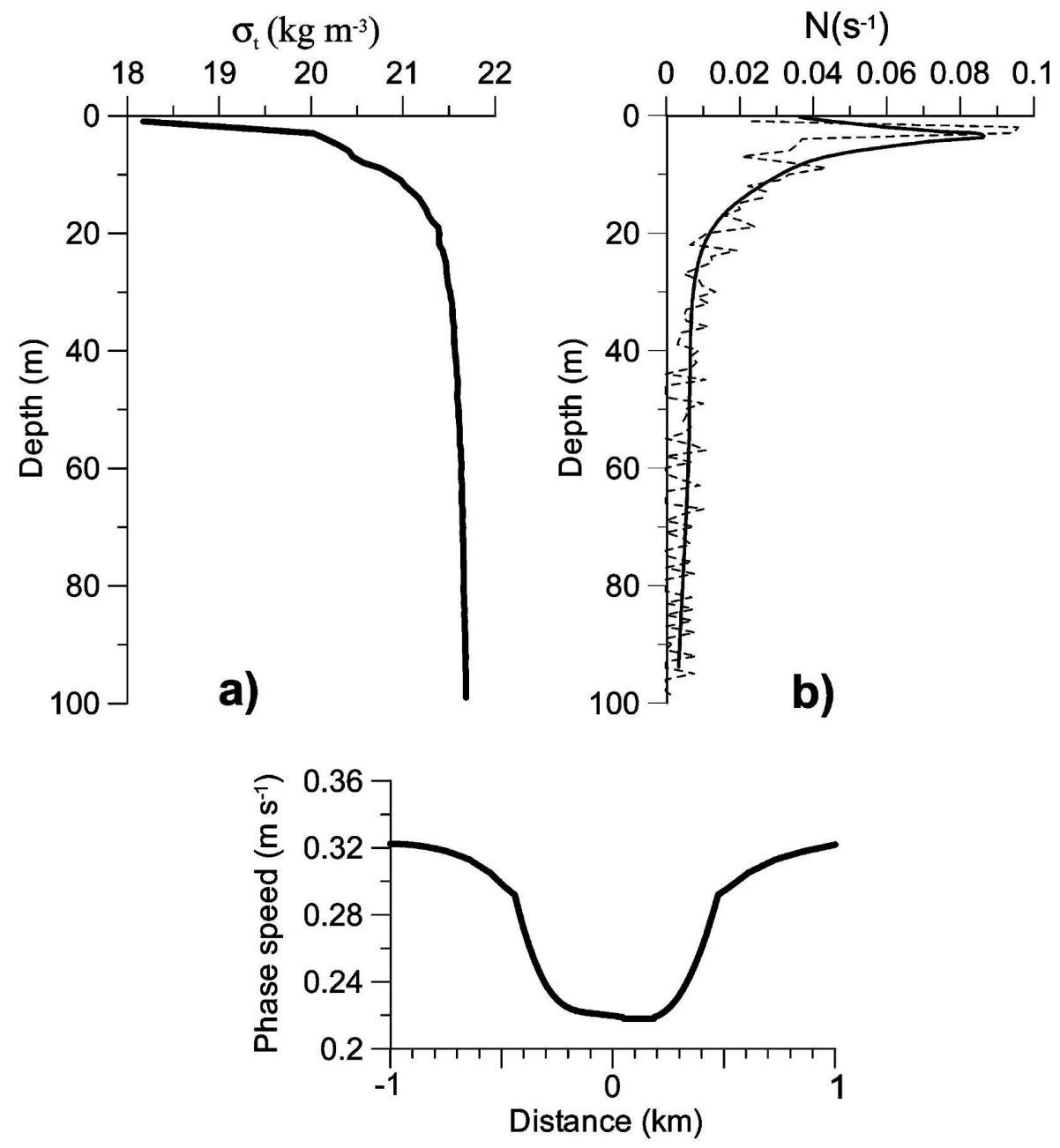

c)

FIG. 5. (a) Conventional density $\sigma_{t}\left(\mathrm{~kg} \mathrm{~m}^{-3}\right)$ profile measured at station RE5. (b) Buoyancy frequency $N\left(\mathrm{~s}^{-1}\right)$ at station RE5: the experimental profile is denoted by a dashed line and a solid line shows its theoretical representation. (c) Distribution of the mode-1 phase speed $\left(\mathrm{m} \mathrm{s}^{-1}\right)$ along the sill.

where the subscript $n$ identifies the direction perpendicular to the bottom surface. The vorticity at the bottom $\Omega_{0}$ is calculated from the streamfunction obtained at the previous temporal step.

At the lateral "liquid" boundaries, "zero" values of perturbation were imposed. To avoid the influence of these boundaries on the modeling results due to the wave reflection, they were distanced from the sill. Thus the leading generated wave does not reach any of the liquid boundaries during the numerical experiment.

Equations (1)-(6) along with zero initial conditions for all unknown variables are solved numerically by means of the alternating-direction implicit method. The detail of numerical procedure can be found in (Vlasenko et al. 2005).
It was useful to perform a $\sigma$ transformation of coordinates $[\sigma=-z / H(x)]$ and to transform the physical domain with variable depth into a rectangular computational area. In the vertical, 140 grid points were used. The channel breadth $2 b(x)$ is decreased from 1660 to $285 \mathrm{~m}$ in the sill area and then increased up to $1080 \mathrm{~m}$ in the upper-basin direction (Fig. 4a). It was found that by taking $\Delta t=1 \mathrm{~s}, \Delta x=2.5 \mathrm{~m}, \Delta z=0.07-1.0 \mathrm{~m}, A_{0}=$ $5 \times 10^{-3} \mathrm{~m}^{2} \mathrm{~s}^{-1}, A_{b}=10^{-4} \mathrm{~m}^{2} \mathrm{~s}^{-1}, k=1, \alpha=1$, and $K_{b}=10^{-5} \mathrm{~m}^{2} \mathrm{~s}^{-1}$, the numerical scheme was very stable.

\section{Froude number analysis}

The model is forced with the tidal flow discharged into the upper basin, $\Psi_{0}=2 b(x) U(x) H(x)$ [see Eq. 


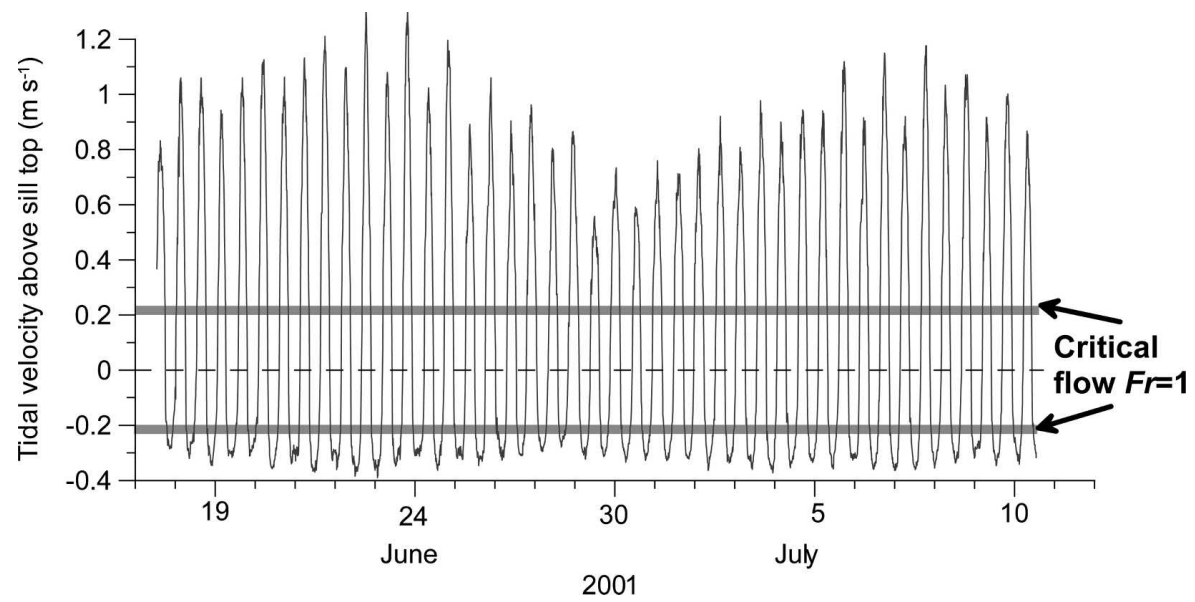

FIG. 6. Depth-averaged cross-sill flow from the sill-moored ADCP (S1) over a 21-day period. Positive values are for tide flooding into the upper basin. Thick horizontal lines divide subcritical $(\mathrm{Fr}<1)$ and supercritical $(\mathrm{Fr}>1)$ regimes.

(4)]. The barotropic flow over the sill was measured by the sill-mounted ADCP (Fig. 6). Using these measurements the forcing flow is specified as $\Psi_{0}=$ $2 b_{\text {top }} U_{\max } H_{\text {top }}$, where $U_{\max }$ is the maximum value of the barotropic tidal velocity above the highest point of the sill (see Fig. 4b). Figure 6 shows a fast short flood tide, reaching $1.3 \mathrm{~m} \mathrm{~s}^{-1}\left(0.6 \mathrm{~m} \mathrm{~s}^{-1}\right)$ at springs (neaps), and a slower longer ebb, reaching $-0.38 \mathrm{~m} \mathrm{~s}^{-1}\left(-0.27 \mathrm{~m} \mathrm{~s}^{-1}\right)$ at springs (neaps). A 14-day bottom pressure record measured by sensors leveled in on either side of the sill reveals asymmetry in the barotropic forcing of the upper basin, presumably as a result of constrictions seaward of the sill (Inall et al. 2004).

Observations show a more than fourfold temporal variability of the tidal forcing, which raises the question of whether Loch Etive can be classified as a jet-type fjord for every tidal cycle, especially during the ebb phase. The answer to this can be found on the basis of a Froude number analysis, with the primary nondimensional parameter controlling the dynamics of stratified flow in the sill area:

$$
\operatorname{Fr}=\frac{U}{c},
$$

where $U$ is tidal velocity and $c$ is the phase speed of internal wave. If Fr is smaller than unity, the waves can freely propagate in the channel and a subcritical regime exists, otherwise $(\mathrm{Fr}>1)$ the internal waves become arrested and energy is released through an internal hydraulic jump.

In the case of stratified fluid we can find Fr for all infinite number of internal modes. Taking into account that the first mode is the fastest wave then its Froude number will be the lowest one. Thus, estimation of the first-mode Fr number can show the hydraulic response of the stratified flow. For arbitrary stratification the phase speed can only be found numerically by solving a boundary value problem (BVP) as shown below.

With a knowledge of the bottom profile (Fig. 4b) and the fluid stratification (Fig. 5b), the local phase speed $c$ of the internal waves and the vertical structure of baroclinic modes $G(z)$ can be estimated from the following BVP:

$$
\frac{d^{2} G}{d z^{2}}+\frac{N^{2}(z)}{c^{2}} G=0 \quad \text { and } \quad G(0)=G(-H)=0
$$

Calculations of the phase speed $c$ based on Eq. (8) show that the phase speed of mode- 1 internal wave increases from $0.22 \mathrm{~m} \mathrm{~s}^{-1}$ on the top of Loch Etive sill to 0.33 $\mathrm{m} \mathrm{s}^{-1}$ in the deep part of the basin (see Fig. 5c). If so, simple calculations show that the maximum Froude number over the sill varies in the range from 1.2 for the neap ebb tide to almost 5.9 for the spring flood phase of the tide. Figure 6 shows that the majority of the flood tide corresponds to a supercritical regime and the ebb tide is also subjected to critical conditions. Thus, based on these estimations, Loch Etive can be classified as a jet-type fjord during flood and ebb phase, which is traditionally characterized by a very weak baroclinic response to tidal forcing. Simultaneous measurements from the middle of Loch Etive presented in Fig. 2 show a significant baroclinic tide. Such a contradiction demands further precise investigation of flow behavior in the vicinity of the sill.

\section{Theoretical and observational investigation of tidal response of Loch Etive}

The study of Loch Etive's response to the tidal forcing approaching spring tides is based on a combination 
of numerical and observational results and their comparison, where appropriate. We start our analysis with the tidal current corresponding to 19 June in Fig. 6 (beginning of the VMADCP measurements in Loch Etive). The maximum of tidal velocity during this cycle was $1 \mathrm{~m} \mathrm{~s}^{-1}$.

Results from the numerical runs showing time series of the density for the first half of the tidal cycle are presented in Fig. 7. Note that in the present case, because of the large value of the velocity of the flow above the sill in comparison with the phase speed of the mode-1 waves (Fig. 5c), the tidal current is strongly supercritical during the substantial part of the flood stage. Figure 7a shows that two systems of unsteady lee waves are generated above both slopes of the sill (fragments I and II). Being trapped by the accelerating supercritical current, these waves are carried away to the lee side of the sill (cf. Figs. 7a and 7b). Here a baroclinic hydraulic jump is formed as a result of the supercritical conditions (Fig. 7c).

The hydraulic jump is swept downstream and arrested for a substantial part of the tidal cycle (for about $3.5 \mathrm{~h}$ ) at a distance of $250 \mathrm{~m}$ from the middle of the sill (see Figs. 7c-e). The jump looks like a solitary wave with a horizontal scale of $50 \mathrm{~m}$ and an amplitude of 25 $\mathrm{m}$. It starts to move upstream as the tidal flux slackens, and by $t=5 \mathrm{~h} 47 \mathrm{~min}$ it propagates $75 \mathrm{~m}$ upstream (Fig. $7 \mathrm{e})$. The jump dramatically attenuates because of the mixing (Figs. 7e,f), and it is almost fully incorporated into a new less-pronounced hydraulic jump, which is formed on the seaward part of the sill during the ebb phase of the tide (Fig. $7 \mathrm{~g}$ ).

Additional information about the dynamics of strong supercritical flow over the sill's crest can be obtained from the comparative analysis of ADCP data collected over the sill and velocity fields found numerically. Figures 8 and 9 represent in situ (Figs. 8a and 9a) and model-predicted (Figs. 8b and 9b) vertical sections of the horizontal velocity for two different moments of flow evolution (for $t=1 \mathrm{~h} 16 \mathrm{~min}$ and $t=2 \mathrm{~h} 30 \mathrm{~min}$ in Figs. 8 and 9, respectively). A first look at these two series shows that the experimentally and numerically derived velocity fields coincide in their general features. Both show the flow separation in the area of the crest of the sill, as predicted for jet-type flow (Farmer and Freeland 1983). In theoretical and experimental fields the separation point can be identified somewhere at the depth between 25 and $35 \mathrm{~m}$.

Moreover in situ and numerical velocities in both series (Figs. 8 and 9) reveal not only large-scale conformity but also coincide in many details. Figure 8 represents an initial stage of tidal cycle $(1 \mathrm{~h}$ after the beginning), which corresponds to the intermediate stage between generation of lee waves (Fig. 7a) and fully developed hydraulic jump (Fig. 7d). Analysis of Figs. 8a and $8 \mathrm{~b}$ along with the density field representing the same moment in time (Fig. 7b) allows one to interpret the measurements more completely and accurately. Intensification of the flow near the bottom, namely, the fragment $\mathrm{a}-\mathrm{a}$ in the experimental velocity field in Fig. 8a, can be found also in Fig. 8b. Both correspond to the downstream-propagating bottom flow, which is clearly seen in the density field (fragment $a-a$ in Fig. 7b) and is the cophase line of internal lee waves. The stagnation area formed above this intensified flow is also clearly seen in both experimental and numerical fields.

The velocity fields presented in Fig. 9 are different from those given in Fig. 8. An evident distinction between them is that in Fig. 9 the flow above the sill crest is intensified near the surface, whereas the stagnation zone is formed near the bottom. An additional stagnation area can be identified near the surface just behind the sill crest. The difference between Figs. 8 and 9 is explained because the latter represents a later stage of the flow evolution $(t=2 \mathrm{~h} 30 \mathrm{~min})$, when a quasistationary hydraulic jump was fully developed downstream of the sill (clearly seen in Fig. 7c). The hydraulic jump leads to descending water (up to $20 \mathrm{~m}$ ) and the formation of a stagnation area near the surface and ahead of the jump.

A definite disagreement in horizontal scales of the intensification and stagnation areas in experimental and numerical fields in Figs. 8 and 9 should be noted. This discrepancy can be explained in terms of the shape of the bottom profile, which differs slightly in the two cases; smoothed theoretical bottom topography, as was mentioned above, was obtained by averaging the real bottom topography, which varies slightly across the channel. However, the agreement between numerical and experimental patterns can be classified as very satisfactory.

The results presented above have shown that being exposed to a strong tidal forcing in the sill area, Loch Etive behaves as a typical jet-type fjordic system with localized baroclinic response. However, the observations at some distance landward of the sill contradict this statement. In situ measurements of temperature and velocity collected by a thermistor chain and ADCP placed at station RE5, a distance of $2 \mathrm{~km}$ from the sill, are presented in Fig. 10a. The temporal variability of temperature reveals the strong $M_{2}$ baroclinic tidal signal with a vertical amplitude of about $10 \mathrm{~m}$. The overlaid velocity field indicates also that the registered signal is in fact a progressive wave, propagating from the sill into the loch. The progressive nature of the baro- 

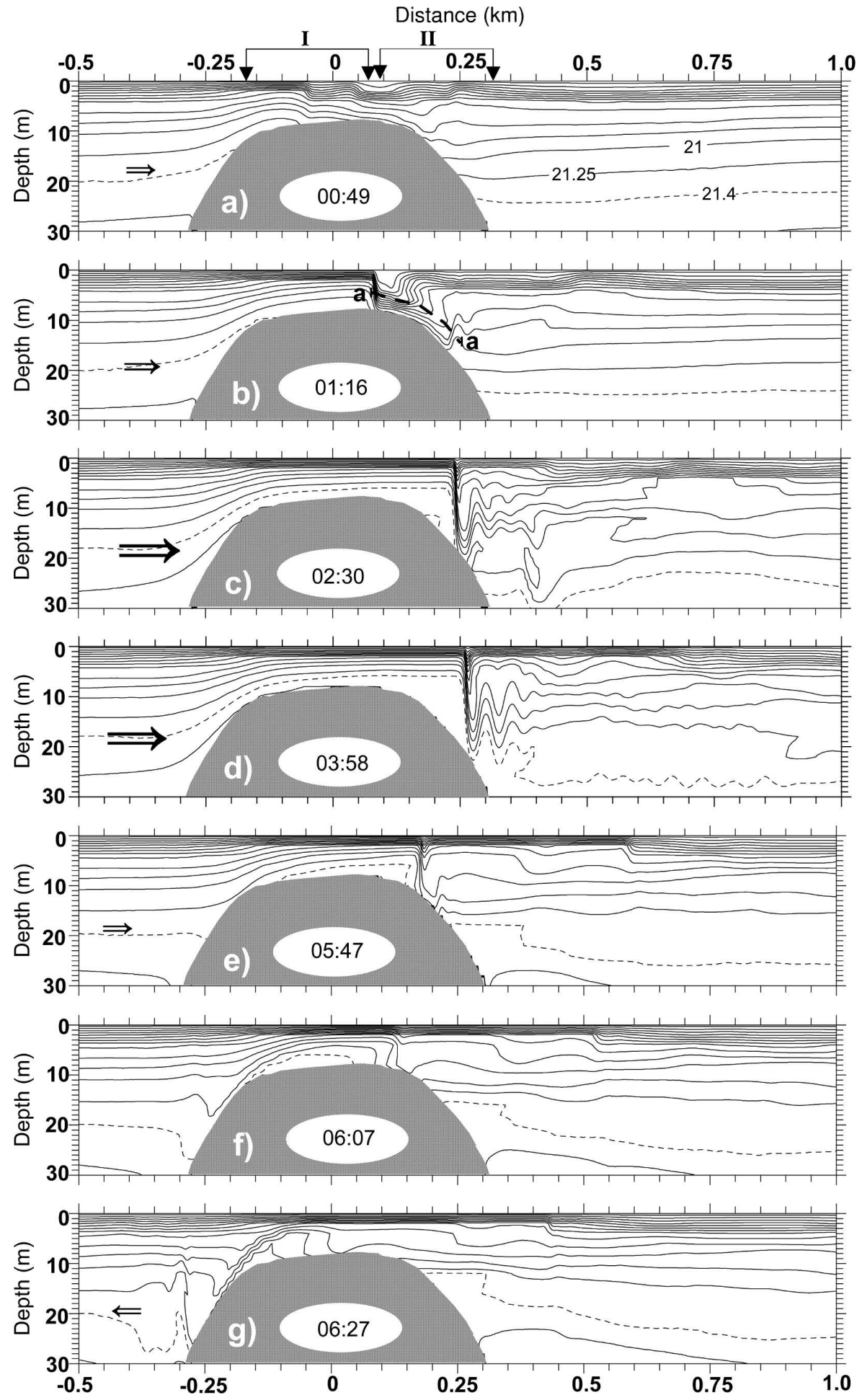

FIG. 7. Model-predicted evolution of the conventional density $\sigma_{t}\left(\mathrm{~kg} \mathrm{~m}^{-3}\right)$ during the first half of the tidal cycle on 19 Jun (beginning of the measurements in Loch Etive) when maximum tidal velocity was $1 \mathrm{~m} \mathrm{~s}^{-1}$. The direction of tide and intensity are given by arrows. The contour interval equals $0.25\left(\mathrm{~kg} \mathrm{~m}^{-3}\right)$. Fragments I and II show two systems of unsteady lee waves. 


\section{Velocity scale $\left(\mathrm{m} \mathrm{s}^{-1}\right)$}

$\begin{array}{llllll}0 & 0.15 & 0.3 & 0.45 & 0.6 & 0.75\end{array}$
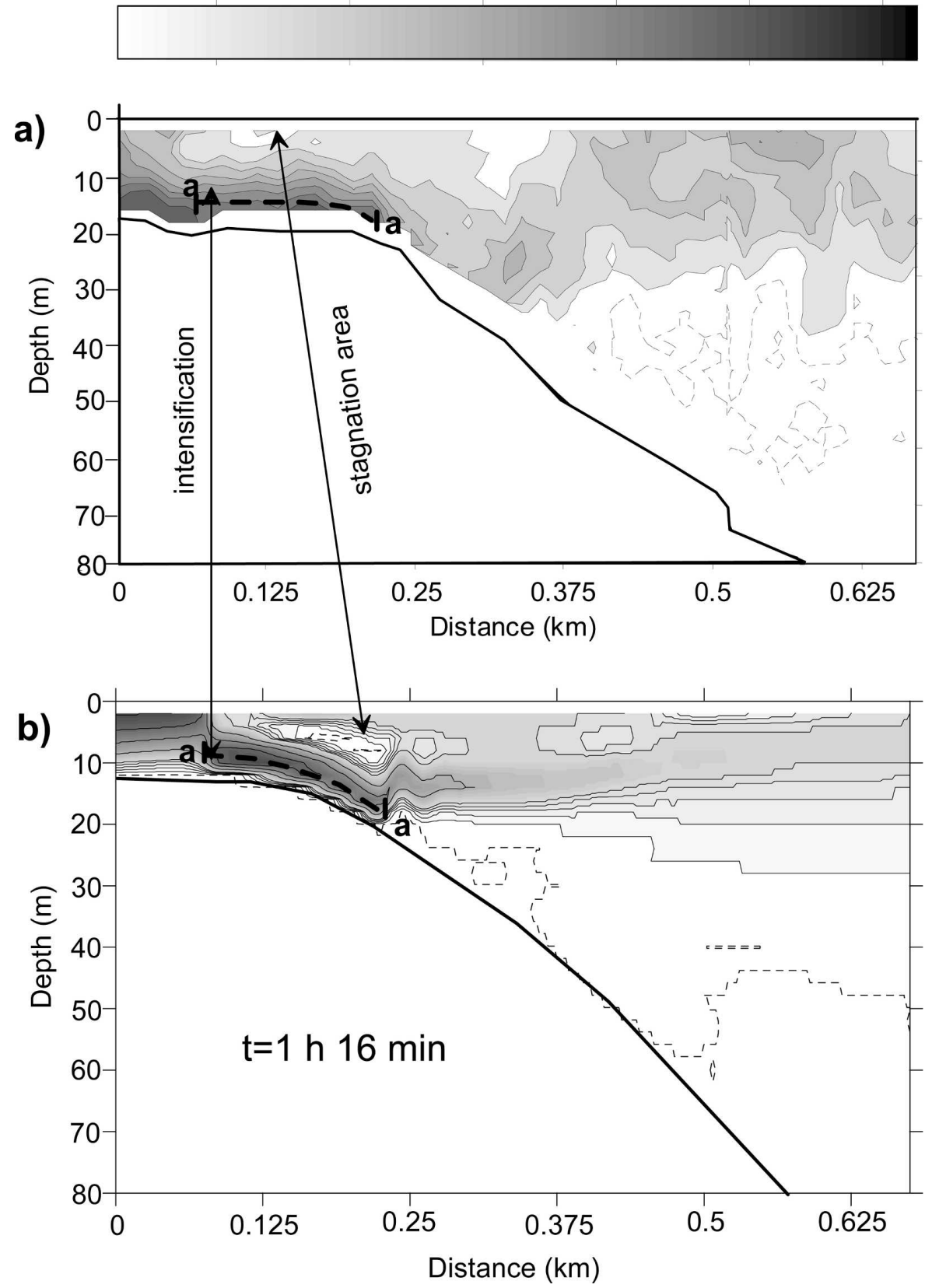

FIG. 8. (a) Observed cross-sill flow during the flood tide from the (left) sill toward (right) RE5 from the vessel-mounted ADCP. Positive values indicate flow from left to right; (b) modelpredicted horizontal velocity field at $1 \mathrm{~h} 16 \mathrm{~min}$ after the beginning of flood tide motion. The fragments a-a denote similar areas of flow intensification.

clinic disturbance is evident from the phase alignment of velocity and isotherm displacement perturbations.

Time series of density sections obtained numerically at the same distance from the sill as station RE5 are shown in Fig. 10b (solid lines). The coincidence between numerical and experimental profiles is remark- able: the form and the amplitude of waves are the same. Both wave series appear asymmetrical in shape, with short steep troughs and longer flatter crests. At first glance the oscillations do not appear to possess the characteristics of linear internal waves. However, it should be noted that the tidal velocity found in the sill 
Velocity scale $\left(\mathrm{m} \mathrm{s}^{-1}\right)$

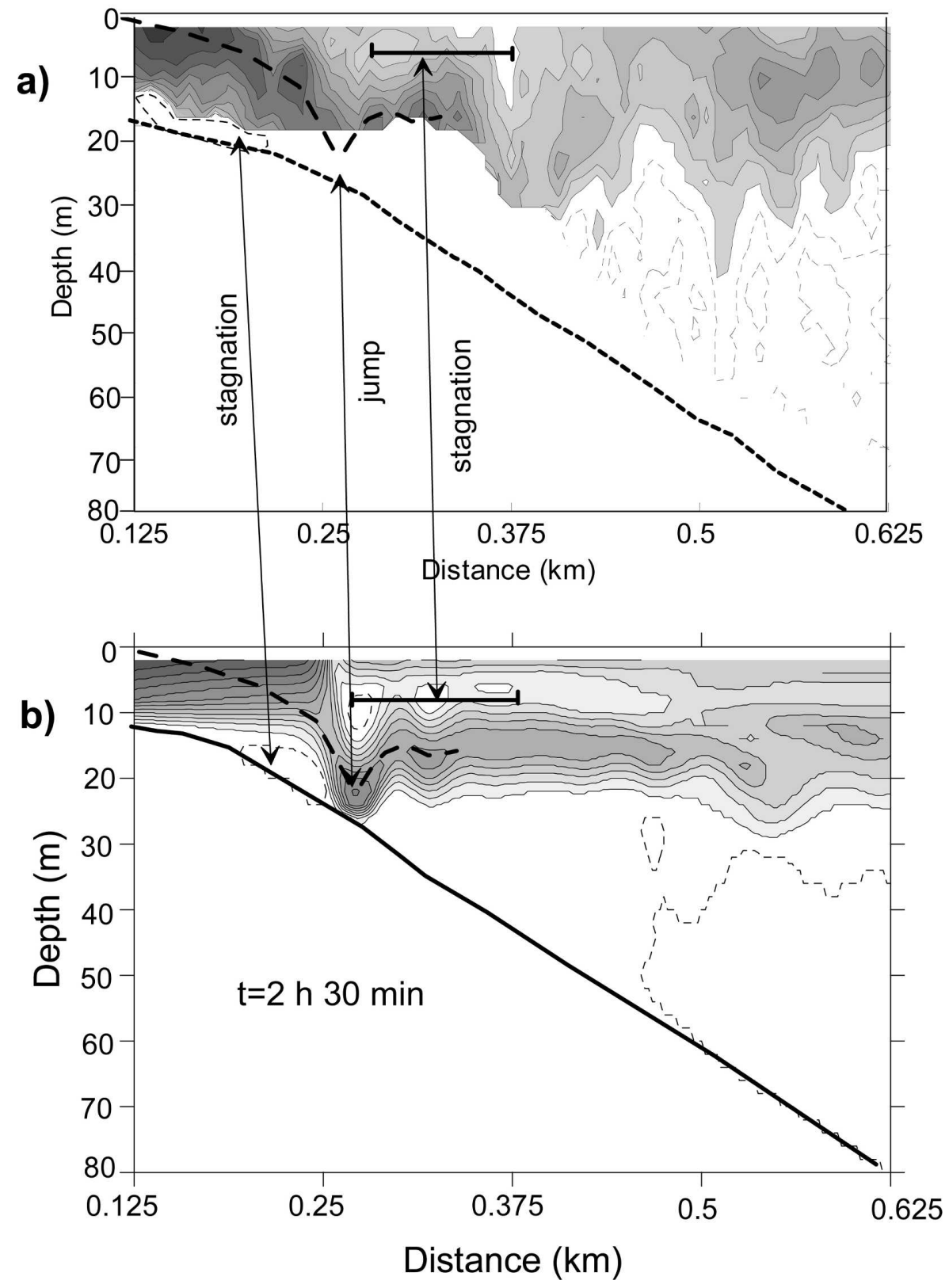

FIG. 9. The same as in Fig. 8 but for $t=2 \mathrm{~h} 30$ min. Thick solid and dashed lines show similar areas of stagnation and intensification, respectively.

area (Fig. 6) is asymmetrical, with a shorter, faster flood phase in comparison with ebb phase. (A second reason for the asymmetry is discussed in the next section.)

Thus, being basically a jet-type fjord, Loch Etive, however, produces a remarkable baroclinic tidal re- sponse. This response appears to be generated on the landward flank of the sill. Note, however, that this suggestion is in conflict with the findings of the previous section that stratified tidal flux separates from the bottom in the area of the sill's crest. As a result, the sepa- 

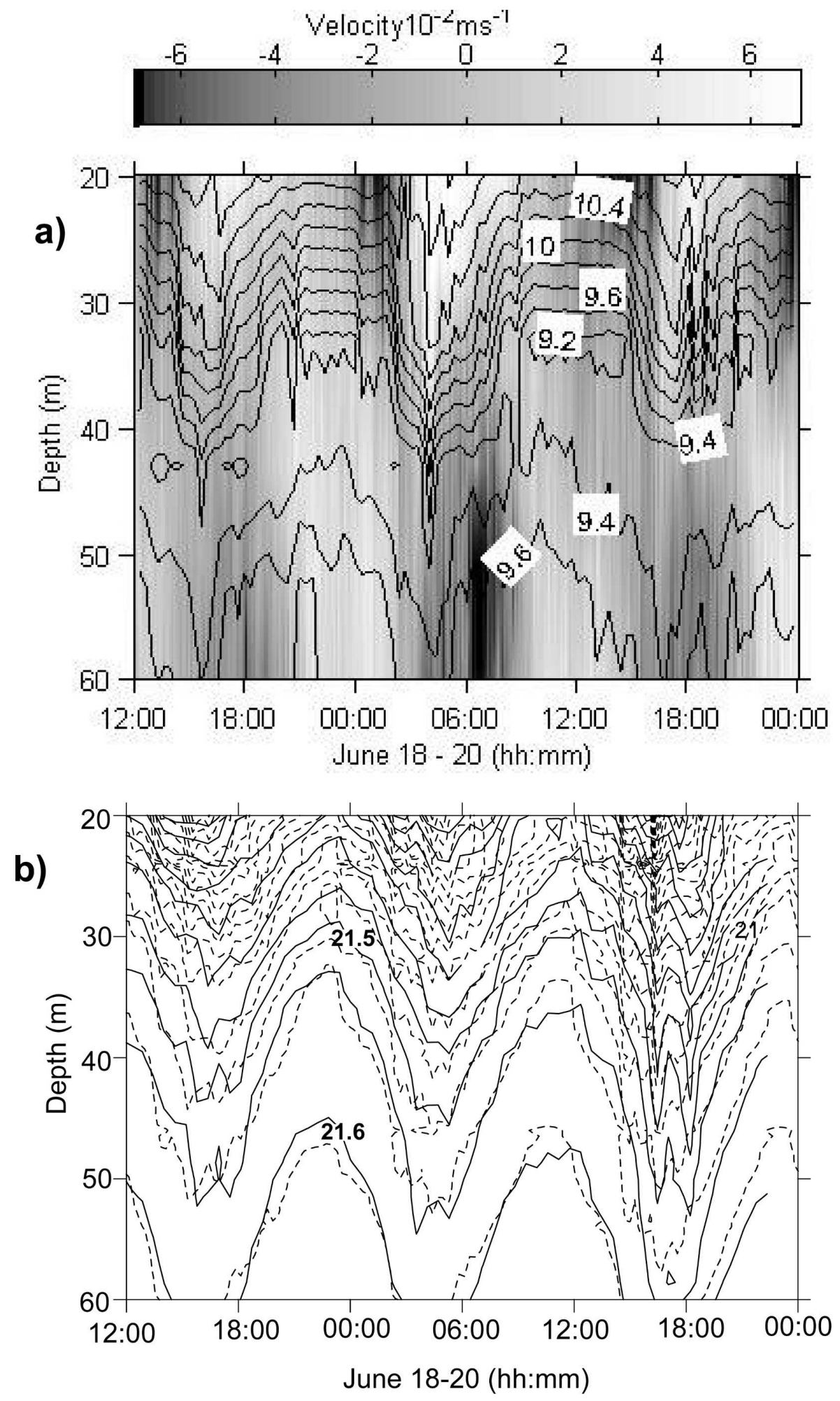

FIG. 10. (a) Vertical structure of along-axis baroclinic currents $\left(10^{-2} \mathrm{~m} \mathrm{~s}^{-1}\right)$ at RE5 on 19 Jun with isotherms overlaid $\left({ }^{\circ} \mathrm{C}\right)$. (b) Modeled vertical density $\left(\mathrm{kg} \mathrm{m}^{-3}\right)$ structure at a distance of 2 $\mathrm{km}$ from the sill (equivalent to RE5 location). Solid lines correspond to real sill. Dashed lines show the density field obtained for truncated sill (25-m top). Depth is in meters. 
rating flow propagates horizontally from the sill as a jet (without streamlines following the topography) and therefore cannot produce vertical oscillations. In fact, the streamlines define a new "effective" upper boundary with a horizontal profile that coincides with the lower boundary of the jet.

An important point to note is that the process of jet formation to the right of the sill takes place during only half of the tidal cycle (the flood phase). The key point in understanding the generation mechanism is that the barotropic water flux reverses during the second half of the tidal cycle (the ebb phase) and water moves seaward. At this stage a jet will form on the seaward side of the sill, but on the landward side the motions will be slow and laminar because of the large cross section of the channel (large depth and width). It should be noted that a similar situation exists on the seaward flank of the sill during flood phase, and this situation is shown in Fig. 7: to the left (seaward) of the sill isolines follow the inclined bottom even though the flux is separated from bottom to the right (landward) of it. A similar process will take place on the landward flank of the sill during the ebb, such that the tidal flow streamlines the bottom topography, produces vertical oscillations, and generates an internal tide.

This mechanism also explains why the baroclinic tidal waves observed in the experiment (Fig. 10a) and obtained numerically (Fig. 10b) are asymmetric: these waves are generated only during one-half of the tidal cycle according to the "half-tidal-period" generation mechanism, so they must possess an asymmetry in their shape.

\section{Spatial distribution of tidal forcing}

To check the ideas formulated above about the possible reasons for internal tide generation, we now perform some quantitative estimates. The first parameter to be analyzed is the distribution of the Froude number along the loch $\operatorname{Fr}(x)$.

Note that the estimates of the Froude number over the inclined bottom across the loch sill may be incorrect in the areas of the flow separation because the profile of the "effective obstacle" defined by the separation streamline does not coincide with real sill topography. However, in the places where tide streamlines follow the topography without separation (to the left of the sill during the flood phase and to the right of it during the ebb) the Froude number can be calculated taking into account the variability of the mode- 1 phase speed $c$ presented in Fig. 5c, as well as the variations of the barotropic tidal velocity $U$ due to depth (Fig. 4a) and width changes (Fig. 4b) in the channel. Figure 11a shows the distribution of the Froude number to the left of the sill for the flood phase of the tidal cycle, while Fig. 11e represents $\operatorname{Fr}(x)$ for the ebb to the right of the sill's crest. Figure 11 consists of two columns, where the left-hand one (Figs. 11a-d) corresponds to the left flank of the sill and the right-hand column (Figs. 11e-h) shows its right flank.

Figure 11 shows that the area with the largest values of Fr coincides with the flat part of the sill. On the other hand it is well known that internal waves are generated by the interaction of tide with inclined topography, and it is unlikely that strong supercritical tidal flow propagating over the flat sill top generates internal waves.

For the ebb tide presented on the right-hand side of Fig. 11, the Froude number is less than one for most of the inclined landward part of the sill (Fig. 11f). To the right of point A in Fig. 11f the Froude number is less than 0.2. The low value of Fr denotes that in this area the generation process on the basis of a linear theory is appropriate. If so, let us estimate the intensity of the internal tide generation force on the basis of the following formula introduced by Baines (1973):

$$
F=\rho_{0} \Psi_{0} z \frac{N^{2}(z)}{2 b(x) \omega}\left(\frac{1}{H}\right)_{x},
$$

where $\omega$ is a tidal frequency. Equation (9) shows that with the given stratification, $N(z)$, the generation of internal waves strictly depends on the value of the tidal discharge $\Psi_{0}$, and the inclination of the bottom topography $H_{x}$.

A smoothed pycnocline Eq. (A8) (shown in appendix A and Fig. A1) is used in the analysis as the background fluid stratification. This profile with the input parameters $H_{p}=3.4 \mathrm{~m}, N_{p}=0.091 \mathrm{~s}^{-1}$, and $\Delta H_{p}=6 \mathrm{~m}$ represents the observed buoyancy frequency very accurately. An advantage of this law of fluid stratification is that it has an analytical solution Eq. (A9) of the boundary value problem Eq. (A6). Therefore the phase speed of internal waves can also be expressed analytically in terms of elementary functions, see Eq. (A11).

Taking this fact into account and presenting the tidal flow as $U(x)=\Psi_{0} / 2 b(x) H(x)$, Eq. (9) can be rewritten in terms of the Froude number and bottom profile $H(x)$ as follows:

$$
F=-\frac{\rho_{0} z N^{2}(z)}{2 \omega \pi} N_{p} \Delta H_{p} \frac{\operatorname{Fr}(x) H_{x}}{p(x) H(x)},
$$

where the function $p(x)$ is described in appendix A. This new Eq. (10) shows that the intensity of the tidal forcing depends on the product of $\operatorname{Fr}(x)$ and a bottom function $H_{x} / H(x) p(x)$.

It can be seen from Eq. (10) that the $x$ - and $z$-dependent parts of the function $F$ are separable, namely, 


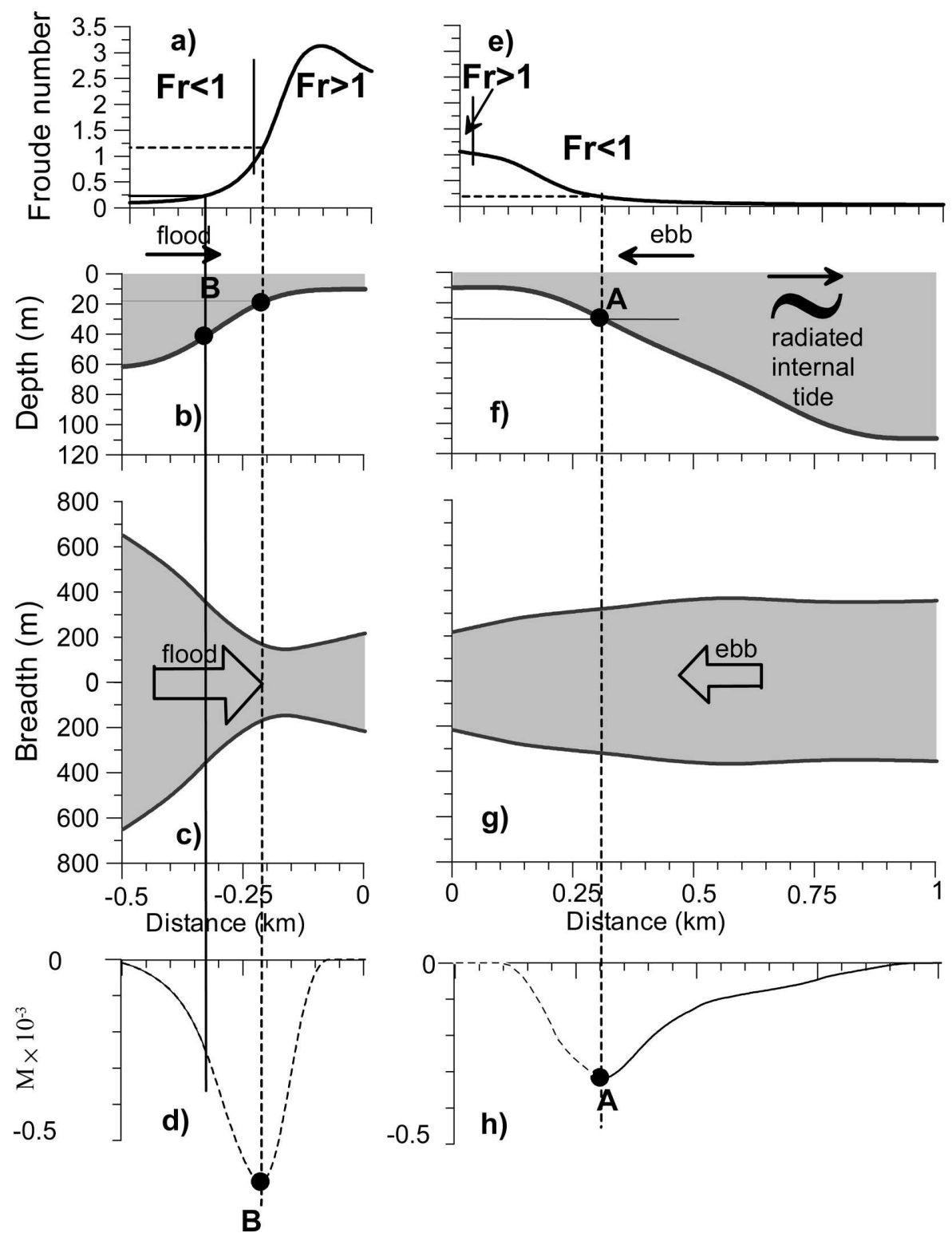

FIG. 11. (a), (e) Froude number; (b), (f) sill depth; (c), (g) channel width; and (d), (h) $M(x)=$ $\operatorname{Fr}(x) H_{x} \Delta H_{p} / H(x) p(x)$ vs distance from sill; (left) negative and (right) positive.

$$
F(x, z)=-\frac{\rho_{0} N_{p} \Delta H_{p}}{2 \omega \pi} D(z) M(x),
$$

where $D(z)=z N^{2}(z)$ and $M(x)=\operatorname{Fr}(x) H_{x} / H(x) p(x)$. It is therefore sufficient for a comparative analysis to consider only the $x$-dependent part of Eq. (10) to evaluate the specific input of different fragments of the sill to the internal tide generation process. The dependence $M(x)$ is shown in Figs. 11d and 11h.

It is clear that Eq. (10) is valid only in a linear case in which $\mathrm{Fr} \ll 1$, although the function $F$ was formally estimated beyond this range (dashed lined in Figs. 11d and 11h). Filled circles marked with letters A and B in Fig. 11 represent the maximum values of the tidal forcing and corresponding positions on the sill's profile. It is seen from Fig. 11a that in case of flood tide the maximum Froude number equals 1.2 in the position of maximal value of tidal forcing, so the linear theory is not valid here. For the ebb tide the maximum value of tidal forcing $F$ to the right of the sill's crest occurs in the place where $\mathrm{Fr}=0.2$. This point at the sill's slope is marked by the letter A (see Fig. 11h).

The analysis presented above shows that even though the top of the sill is subjected to strong supercritical 
conditions, its specific input into the energy transformation from barotropic tide to baroclinic waves can be considered as negligible, and a linear response of the loch sill produced to the left of point B in Fig. 11b and to the right of point $\mathrm{A}$ in Fig. 11f can be basically expected.

The following numerical experiment was carried out to test this idea. Let us imagine that Loch Etive has a deeper sill with depth $25 \mathrm{~m}$ instead of $10 \mathrm{~m}$. In such a case the absence of the strongly nonlinear crest-sill effects will be reduced, but the linear part of the solution should remain the same because, according to the graphics of Fig. 11, the area, which is responsible for the generation of linear internal waves, still remains in the new sill configuration. If so, the linear part of the wave field inside the loch even after the "top-cut" procedure should be the same as for the original topography. Analysis of the wave fields generated by the interaction of the tide with two different sill topographies (original and truncated) can confirm or reject this hypothesis. Figure $10 \mathrm{~b}$ contains time series of isopycnals obtained 2 $\mathrm{km}$ off the sill where solid lines correspond to real sill and dashed lines were found for ad hoc $(25 \mathrm{~m})$ configuration. Comparison of the density fields shows that both look very alike with only small differences in details.

\section{Budget of tidal energy}

The energy of the incoming barotropic tidal wave over the sill splits into several parts (e.g., Klymak and Gregg 2004; Inall et al. 2005). A large part is lost because of frictional retardation in the bottom boundary layer. Another part is radiated from the sill as barotropic and baroclinic waves. An important sink of energy is the generation of baroclinic tides.

According to Farmer and Freeland (1983), averaging over the tidal cycle the mean dissipation flux $J$ lost over the sill is expressed in terms of barotropic tidal current amplitude $U_{\max }$ and the amplitude of the tidal surface elevation $a_{\max }$ over the sill as follows:

$$
J=\frac{1}{2} \bar{\rho}_{0} g A_{s} a_{\max } U_{\max } \cos (\phi),
$$

where $A_{s}$ is the cross-sectional area on top of the sill, and $\phi$ is the phase difference between the cross-sill barotropic flow and the free surface elevation over the sill. According to observations (Inall et al. 2004), the phase difference $\phi$ was equal to $81^{\circ}$ at spring tide, which indicates partial damping of the barotropic standing waves landward to the sill. The linear error on this phase difference, estimated from the least squares fitting of an $M_{2}$ signal to the velocity and surface elevation records, is $\pm 1.5^{\circ}$.
For the conditions at Loch Etive Eq. (12) predicts $1.2 \pm 0.2 \times 10^{6} \mathrm{~W}$ energy loss of the surface tide (estimations for 19 June), which is about $16 \%$ of the total incoming barotropic tidal energy (Inall et al. 2004). The part of barotropic tidal energy transformed directly to baroclinic tides and propagating landward as a purely progressive wave can be estimated from the observations at station RE5 (Fig. 10a) and with the use of the model results obtained at this site (Fig. 10b). Both time series show that vertical displacements of isopycnals have tidal periodicity and can be treated as a predominantly first baroclinic-mode progressive wave (evidenced from the phase relationship between velocity and isopycnal displacement; Fig. 10).

The amplitude $a_{1}$ of vertical isopycnal displacements is equal to about $10 \mathrm{~m}$. Taking this value as an amplitude of baroclinic tidal wave propagating from the sill, one can apply Eq. (B5) developed in appendix B to estimate the horizontal energy flux $J_{x}$ transported by the first-mode internal tidal wave. Application of Eq. (B5) to the monochromatic wave with amplitude of $a_{1}=10 \mathrm{~m}$ propagating in a stratified fluid described by a smoothed pycnocline Eq. (A8) with parameters $H_{p}=$ $3.4 \mathrm{~m}, N_{p}=0.092 \mathrm{~s}^{-1}$, and $\Delta H_{P}=6 \mathrm{~m}$ gives a value of the horizontal energy flux $\left(J_{1}\right.$ integrated through the horizontal cross section of the loch at the position of station RE5) equal to $0.34 \times 10^{6} \mathrm{~W}$. From this estimate it is clear that almost $30 \%$ of the barotropic tidal energy loss in the sill's area is transformed into a baroclinic tidal wave propagating landward. On the basis of Fig. 11d a comparable fraction of energy (or greater fraction, depending on the Froude number at which the linear theory breaks down) is lost during the generation of waves propagating seaward. However, it should be noted that this prediction is based purely on the linear Baines (1973) formulation, without further modeling or observational support.

These calculations of the baroclinic tidal drag for Loch Etive are similar to estimations performed by Klymak and Gregg (2004) of the tidal power withdrawn from barotropic tide into baroclinic tides for Knight Inlet (British Columbia, Canada). They found after a thorough analysis of the experimental data that twothirds of the incoming tidal energy radiates away from the sill as internal waves, whereas only one-third is lost in the sill area as a result of the processes of eddy generation and internal and skin friction. In fact, this result confirmed the hypothesis formulated two decades ago by Stacey $(1984,1985)$, who investigated the energy balance in the Observatory and Knight Inlets. Despite the fact that the maximum Froude number in both these fjords was close to unity, Stacey (1985) applied a simple linear model for calculation of the effi- 
ciency of the baroclinic wave drag and found that a substantial part of barotropic tidal energy was transformed into internal waves. Moreover, the use of a simplified bottom topography in his model, namely, a knife-edge barrier instead of the real profiles, can lead one to the conclusion that strongly nonlinear processes occurring around the sill's crest (viz. generation of the lee waves, hydraulic jumps) make a small impact on the total baroclinic tidal drag. In general, this conclusion was confirmed by Klymak and Gregg (2004) for Knight Inlet and by this study of Loch Etive.

\section{Summary and conclusions}

The classification of fjords into jet- and wave-type basins began from the July-December 1986 field program of Stigebrandt and Aure (1989), which included 30 different fjords with 47 different sill basins. Having data from many sill basins, the idea was to find a generic relationship between the energy flux from barotropic to internal tides and jets and the rate of work actually performed by turbulence against the buoyancy forces. In fjords, internal tides are basically generated by the interaction of a barotropic tidal wave with the sills. If the velocity of the tidal flow is relatively large it was hypothesized that the tide is too fast to generate internal waves over the sill and the basin is considered a jet-type fjord.

To specify whether a fjord is of jet or wave type, Stigebrandt and Aure (1989) used the densimetric Froude number to be larger or smaller than $2 / 3$. The Froude number was defined as the ratio between the maximal value of mean tidal phase speed in the sill section $u_{s 0}$ and phase speed $c_{i}$ of internal waves. To find the value of $c_{i}$ a simple two-layer model was used, which incorporated the depth of the density interface located at the sill's top, and $c_{i}$ is given by the standard formula

$$
c_{i}=\left\{g\left(\rho_{2}-\rho_{1}\right) / \rho_{2}\left[H_{t} H_{b} /\left(H_{t}+H_{b}\right)\right]\right\}^{1 / 2},
$$

where $\rho_{1}\left(\rho_{2}\right)$ is the mean density above (below) the interface, and $H_{t}\left(H_{b}\right)$ is the depth of the upper (lower) layer.

Thus for the mean value of tidal velocity above the sill in the upper part of Loch Etive of $u_{s 0}=1 \mathrm{~m} \mathrm{~s}^{-1}$ and phase speed of the internal tidal wave found by Eq. (13) of $c_{i}=0.43 \mathrm{~m} \mathrm{~s}^{-1}$, Froude number $\mathrm{Fr}=2.3$ and Loch Etive should be considered as jet-type basin for which generation of internal waves is suppressed. In the case of a continuously stratified fluid it follows from the BVP, Eq. (8), that the actual Froude number can reach a value of 5.9. So, only a weak baroclinic tidal response might be anticipated in Loch Etive. However, in situ measurements (Figs. 2 and 10) made several kilometers distant from the sill revealed a remarkable baroclinic tidal signal, which allowed us to make the conclusion that a jet tide nevertheless generates significant internal tidal waves.

To determine the nature of the internal tide generation mechanism, analysis of the tidal regime in the area of the Loch Etive sill was performed on the basis of in situ data and the results of a numerical model. In comparison with the recently published model results by Xing and Davies (2006) we used an asymmetrical tidal forcing for ebb and flood phase, real fluid stratification, and variable cross section of the loch. It was found that the crest of the sill, with a depth of approximately $10 \mathrm{~m}$, is subjected to strong supercritical conditions with the development of flow separation just above the sill's crest. This, in turn, leads to a weak nonlinear baroclinic wave response, as is expected for jet-type fjordic systems. On the other hand, observations and numerical results also revealed the presence of a linear tidal internal wave with an amplitude of up to $10 \mathrm{~m}$, several kilometers from the constriction. Analysis of tidal forcing allowed us to identify the place of their generation with the help of Eq. (10) [or Eq. (11)]. Linear baroclinic tidal waves are excited during the ebb tide over the basic part of the inner flank of the sill at a depth below $30 \mathrm{~m}$, where local Froude number is substantially less than unity. It was found that almost $30 \%$ of the barotropic tidal energy loss in the sill's area is transformed into a baroclinic tidal wave propagating landward. Based on the linear theory it is likely that a comparable or greater fraction of barotropic energy is partitioned to the generation of waves propagating seaward.

In terms of the classification of fjords as jet type or wave type, Loch Etive possesses characteristics of both: a very weak nonlinear response due to strong supercritical conditions with flow separation over the sill is combined with a remarkable linear signal produced by the rest of the obstacle. It has more recently been acknowledged that jet-type fjords can also generate internal tides (e.g., Allen and Simpson 1998; Stigebrandt 1999; Tinis and Pond 2001), but the generation mechanism demonstrated here has not hitherto been discussed in detail.

In this respect Loch Etive can be referred to as a "hybrid type" fjord, which is probably more of an appropriate classification for many other fjordic systems. The importance of this result is that significantly more energy than hitherto indicated may be available for diapycnal buoyancy fluxes in the interior of jet-type fjords. This has implications for estimates of renewal periodicity and consequently estimates of the risk of an adverse biochemical status of the deep waters of many fjords (e.g., anoxia and eutrophication). 
Acknowledgments. This work was supported by the Natural Environment Research Council under Grant NE/C50747X/1, INTAS Grant 03-51-3728, and SAMS NERC Northern Seas Program. We thank two anonymous reviewers for great attention to the paper and valuable recommendations on the improvement of its content.

\section{APPENDIX A}

\section{Boundary Value Problem for Smoothed Pycnocline}

In the linear case the governing system of equations for internal waves reads

$$
\begin{aligned}
u_{t} & =-\tilde{P}_{x} / \rho_{0}, \quad w_{t}=-\tilde{P}_{z} / \rho_{0}-g \tilde{\rho} / \bar{\rho}_{0}, \\
\tilde{\rho}_{t}+w \rho_{0 z} & =0, \quad \text { and } \quad u_{x}+w_{z}=0 .
\end{aligned}
$$

Here $\tilde{P}$ is the wave-induced pressure; all other designations are the same as in section 2 . For periodic motions

$$
\{u, w, \tilde{P}, \rho\}=\{\stackrel{\circ}{\dot{u}} \stackrel{\circ}{w}, \stackrel{\circ}{P}, \stackrel{\circ}{\rho}\}(x, z) \exp (i \sigma t) .
$$

The equation system (Al) after the introduction of a streamfunction $\psi\left(u=\psi_{z}, w=-\psi_{x}\right)$ is reduced to a single differential equation

$$
\psi_{z z}-\left\{\left[N^{2}(z)-\sigma^{2}\right] \sigma^{2}\right\} \psi_{x x}=0 .
$$

Appropriate boundary conditions for baroclinic wave motions are

$$
\psi(x, 0)=\psi(x,-H)=0 .
$$

The equation system (A3) and (A4) admits a periodical solution

$$
\psi=g_{j}(z) \exp \left( \pm i k_{j} x\right)
$$

where $g_{j}(z)$ and $k_{j}$ are the vertical structure function and the wavenumber of $j$ th baroclinic mode, respectively. The following BVP is valid for the definition of $g_{j}(z)$ and $k_{j}$ :

$$
\begin{aligned}
g_{j}^{\prime \prime}+\left[N^{2}(z)-\sigma^{2}\right] / \sigma^{2} k_{j}^{2} g_{j} & =0 \quad \text { and } \\
g_{j}(0) & =g_{j}(-H)=0,
\end{aligned}
$$

where primes denote second derivative with respect to $z$.

In a very general case of an arbitrary stratified fluid, the BVP Eq. (A6) can be solved only numerically. However, there are several particular density profiles that allow analytical representation of the eigenvalues and functions. Probably the most general is the following profile:

$$
N^{2}(z)=\sigma^{2}+\sigma^{2} /\left[a_{1}\left(z+a_{2}\right)^{2}+a_{3}\right]^{2} .
$$

It presents a smoothed pycnocline with thickness of stratified layer $\Delta H_{p}$ and maximum value $N_{p}$ at the

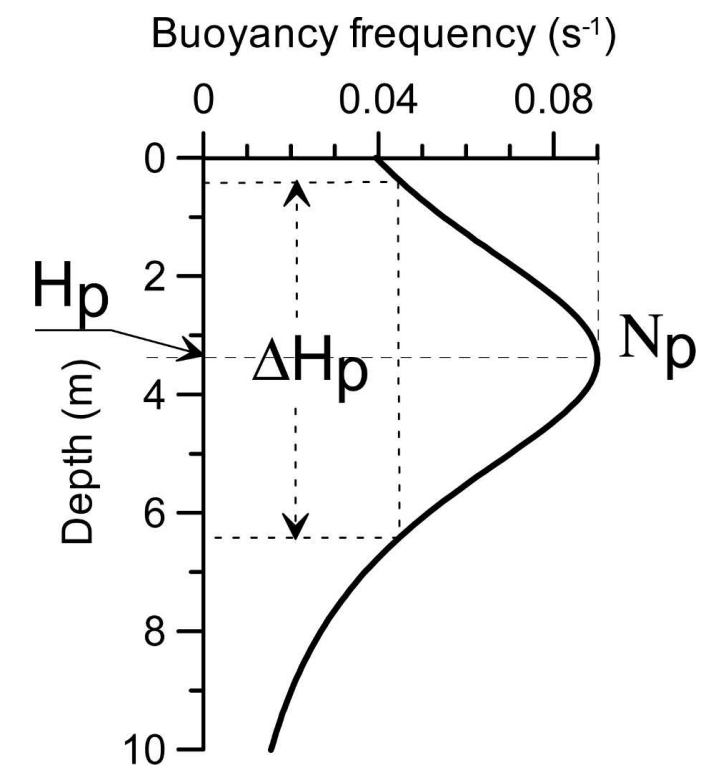

FIG. A1. Analytic representation of the vertical distribution of buoyancy frequency with parameters $N_{p}=0.092 \mathrm{~s}^{-1}, H_{p}=3.4 \mathrm{~m}$, and $\Delta H_{p}=6 \mathrm{~m}$.

depth $H_{p}$ (see Fig. Al). Parameters $a_{1}, a_{2}$, and $a_{3}$ are expressed in terms of $\Delta H_{p}, N_{p}$, and $H_{p}$ as follows:

$$
\begin{aligned}
& a_{1}=\frac{4 \sigma}{\Delta H_{p}^{2}}\left\{\frac{1}{\left[\left(N_{p}^{2} / 4\right)-\sigma^{2}\right]^{1 / 2}}-\frac{1}{\left(N_{p}^{2}-\sigma^{2}\right)^{1 / 2}}\right\}, \\
& a_{2}=H_{p}, \quad \text { and } \quad a_{3}=\frac{\sigma}{\left(N_{p}^{2}-\sigma^{2}\right)^{1 / 2}} .
\end{aligned}
$$

In a very important particular case $N_{p}^{2} \gg \sigma^{2}$, which is normally valid for the ocean, parameters $a_{1}, a_{2}, a_{3}$, and the buoyancy frequency profile $N(z)$ with a very good accuracy can be simplified to the following form:

$$
\begin{aligned}
a_{1} & \cong 4 \sigma / \Delta H_{p}^{2} N_{p}, \quad a_{2}=H_{p}, \quad a_{3} \cong \sigma / N_{p} \\
N(z) & \cong \frac{N_{p}}{\left[4\left(z+H_{p}\right)^{2} / \Delta H_{p}^{2}+1\right]} .
\end{aligned}
$$

In Vlasenko et al. (2005) it is shown that an analytical solution Eq. (A5) for the considered profile reads

$$
\begin{aligned}
\psi & =A_{j} \alpha \sin \left(\frac{j \pi z_{1}}{h}\right) \exp \left( \pm i k_{j} x\right), \\
k_{j} & =\left[\left(\frac{j \pi z_{1}}{h}\right)^{2}-a_{1} a_{3}\right]^{1 / 2}, j=1,2, \ldots
\end{aligned}
$$

Here $A_{j}$ is an arbitrary amplitude of the streamfunction of $j$ th mode; $\alpha=\left[a_{1}\left(z+a_{2}\right)^{2}+a_{3}\right]^{1 / 2} ; h=z_{1}(-H)$; and $z_{1}(z)$ is expressed by the following formula

$$
z_{1}(z)=\frac{\arctan \left[a_{4}\left(z+a_{2}\right)\right]+\arctan \left(a_{4} a_{2}\right)}{\left(a_{1} a_{3}\right)^{1 / 2}} .
$$


Here $a_{4}=\left(a_{1} / a_{3}\right)^{1 / 2}$. For practical use the phase speed $c_{j}$ can be expressed in terms of the parameters of pycnocline $N_{p}, H_{p}$, and $\Delta H_{p}$ as follows:

$$
c_{j}=\sigma / k_{j} \cong \frac{N_{p} \Delta H_{p}}{2 p_{j}(x)},
$$

where

$$
\begin{aligned}
p_{j}(x) & =\left[(j \pi)^{2} /\left(\arctan \Gamma_{1}-\arctan \Gamma_{2}\right)^{2}-1\right]^{1 / 2}, \\
\Gamma_{1} & =2\left[H_{p}-H(x)\right] / \Delta H_{p}, \quad \text { and } \Gamma_{2}=2 H_{p} / \Delta H_{p} .
\end{aligned}
$$

\section{APPENDIX B}

\section{Energy Flux of Baroclinic Tidal Wave}

The equation system ( $\mathrm{Al}$ ) for infinitesimal internal waves can be rewritten in the form of the law of energy conservation as follows:

$$
\frac{1}{2}\left(u^{2}+w^{2}+N^{2} \xi^{2}\right)_{t}+(\tilde{P} u)_{x}+(\tilde{P} w)_{z}=0,
$$

where $\xi$ is the isopycnal wave displacement and $\xi_{t}=w$. It is evident from Eq. (Bl) that the change of total energy within a fluid volume is equal to the total energy flux through the boundaries of this volume. Considering the energy flux radiated from the sill's area, it is necessary to calculate its horizontal component $J_{x}$ integrated through a vertical cross section from the free surface to the bottom:

$$
J_{x}=\int_{-H}^{0} \tilde{P} u d z .
$$

The expressions for the horizontal velocity component $u$ and the pressure $\tilde{P}$ can be found from system Eq. (Al). For the smoothed pycnocline Eq. (A7), which allows the analytical solution for the propagating internal waves Eq. (A9), the functions $u$ and the derivative $\tilde{P}_{z}$ are also expressed analytically as follows:

$\tilde{P}_{z}=\frac{A_{j} \bar{\rho}_{0} \sigma k_{j}}{\alpha^{3}} \sin \left(\frac{j \pi z_{1}}{h}\right) \exp \left(i k_{j} x\right) \quad$ and

$u=A_{j}\left[\frac{a_{1}\left(z+a_{2}\right)}{\alpha}+\frac{j \pi}{h \alpha^{3}} \cos \left(\frac{j \pi z_{1}}{h}\right)\right] \exp \left(i k_{j} x\right)$.

Here dependence $z_{1}(z)$ is given by Eq. (A10).

Substituting Eqs. (B3) and (B4) into Eq. (B2) and integrating through the water column from the bottom to the surface and applying standard routine proce- dures, it is possible to find a very simple analytical expression for the horizontal energy flux $J_{x}$ :

$$
J_{x}=0.25 \sigma h k_{j} A_{j}^{2} .
$$

Here an amplitude of the streamfunction $A_{j}$ of $j$ th baroclinic mode can be easily calculated from the maximum vertical wave displacement, taking into account that $\xi_{t}=w=-\psi_{x}$.

\section{REFERENCES}

Allen, G. L., and J. H. Simpson, 1998: Reflection of the internal tide in Upper Loch Linnhe, a Scottish fjord. Estuarine Coastal Shelf Sci., 46, 683-701.

Baines, P. G., 1973: The generation of internal tides by flat-bump topography. Deep-Sea Res., 20, 179-206.

Farmer, D. M., and H. Freeland, 1983: The physical oceanography of fjords. Progress in Oceanography, Vol. 12, Pergamon Press, 147-220.

Inall, M., F. Cottier, C. Griffits, and T. Rippeth, 2004: Sill dynamics and energy transformation in a jet fjord. Ocean Dyn., 54, 307-314.

—, T. Rippeth, C. Griffiths, and P. Wiles, 2005: Evolution and distribution of TKE production and dissipation within stratified flow over topography. Geophys. Res. Lett., 32, L08607, doi:10.1029/2004GL022289.

Klymak, J. M., and M. C. Gregg, 2004: Tidally generated turbulence over the Knight Inlet sill. J. Phys. Oceanogr., 34, 11351151.

Liungman, O., 2000: Tidally forced internal wave mixing in $k-\epsilon$ model framework applied to fjord basins. J. Phys. Oceanogr., 30, 352-368.

Pacanowski, R. C., and S. G. H. Philander, 1981: Parameterization of vertical mixing in numerical models of tropical oceans. $J$. Phys. Oceanogr., 11, 1443-1451.

Stacey, M. W., 1984: The interaction of tides with the sill of a tidally energetic inlet. J. Phys. Oceanogr., 14, 1105-1117.

_ 1985: Some aspects of the internal tide in Knight Inlet, British Columbia. J. Phys. Oceanogr., 15, 1652-1661.

Stashchuk, N., and K. Hutter, 2001: Modelling of water exchange through the strait of the Dardanelles. Cont. Shelf Res., 21, 1361-1382.

Stigebrandt, A., 1999: Resistance to baroclinic tidal flow in straits by baroclinic wave drag. J. Phys. Oceanogr., 29, 191-197.

— J. Phys. Oceanogr., 19, 917-926.

Tinis, S. W., and S. Pond, 2001: Tidal energy dissipation at the sill of Sechelt Inlet, British Columbia. J. Phys. Oceanogr., 31, 3365-3373.

Vlasenko, V., N. Stashchuk, and K. Hutter, 2002: Water exchange in fjords induced by tidally generated internal lee waves. Dyn. Atmos. Oceans, 35, 63-89.

$\longrightarrow,-$, and — 2005: Baroclinic Tides: Theoretical Modeling and Observational Evidence. Cambridge University Press, $351 \mathrm{pp}$.

Xing, J., and A. M. Davies, 2006: Processes influencing tidal mixing in the region of sills. Geophys. Res. Lett., 33, L04603, doi:10.1029/2005GL025226. 